Supplement of Saf. Nucl. Waste Disposal, 1, 3-4, 2021

https://doi.org/10.5194/sand-1-3-2021-supplement

(c) Author(s) 2021. CC BY 4.0 License.

Supplement of

\title{
Development of a mobile, automated, optical inspection system for radioactive barrels
}

\section{Tania Barretto et al.}

Correspondence to: Tania Barretto (tania.barretto@kit.edu) and Eric Rentschler (eric.rentschler@kit.edu)

The copyright of individual parts of the supplement might differ from the article licence. 
Karlsruhe Institute of Technology

\section{EMOS: Development of a mobile, automated, optical inspection system for radioactive drums}

Tania Barretto, Eric Rentschler, Melanie Müßle

Institute of Technology and Management in Construction (TMB) - Deconstruction and Decommissioning of Conventional and Nuclear Buildings
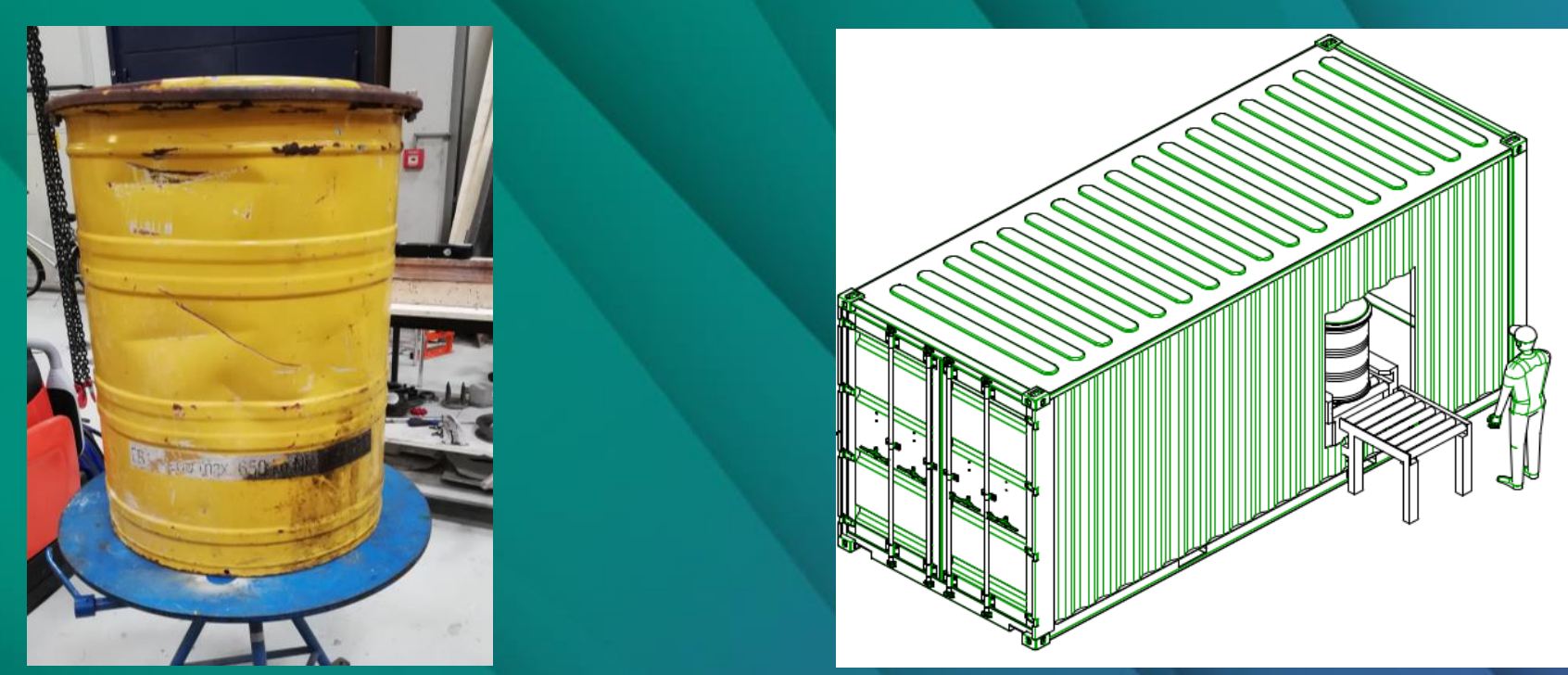

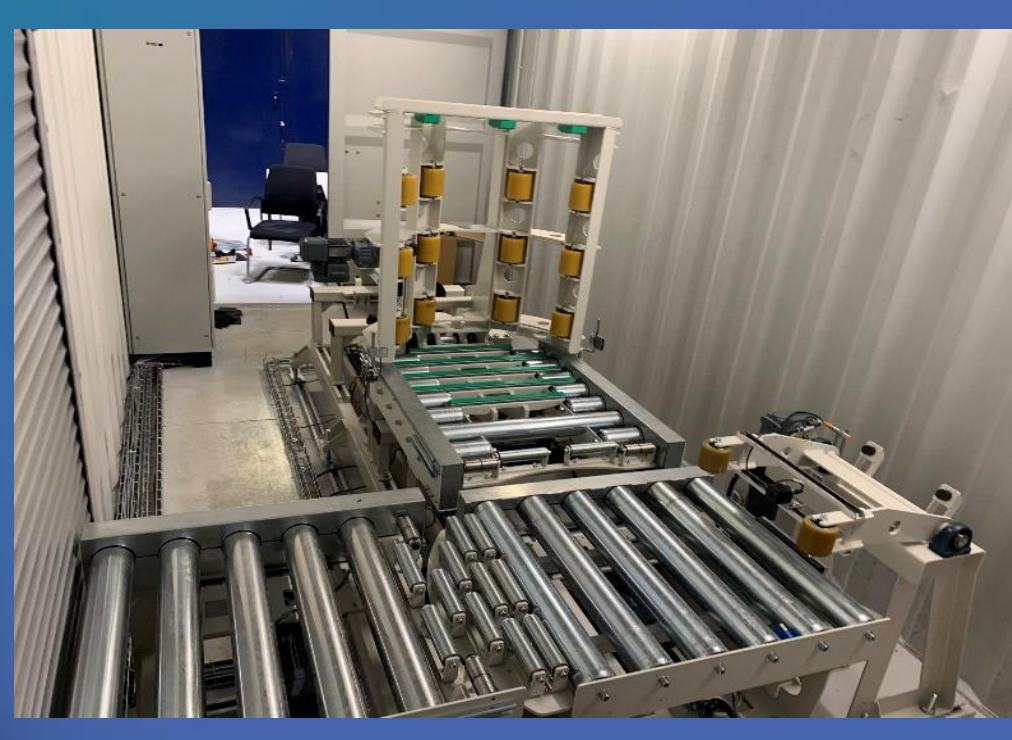

www.kit.edu 


\section{Agenda}

- The research project - EMOS

- Field of application

- Goals

- Concept

- Requirements and boundary conditions

- Setting of Inspection unit and components

- Inspection process

- Outlook

- Time line 


\section{The research project - EMOS}

EMOS - Development of a mobile, automated, optical inspection system for radioactive drums

- Sponsored by:

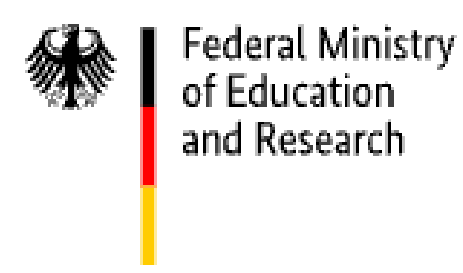

- BMBF Sponsoring Programme „Research for the dismantling of nuclear facilities “ (FORKA)

- Sponsoring number BMBF: FKZ $15 S 9420$

- Research cooperation within the KIT

Institute of Technology and Management in Construction (TMB)

- Institute of Photogrammetry and Remote Sensing (IPF) 


\section{Field of application}

Problem:

- Detection of geometry and corrosion damage to the drum

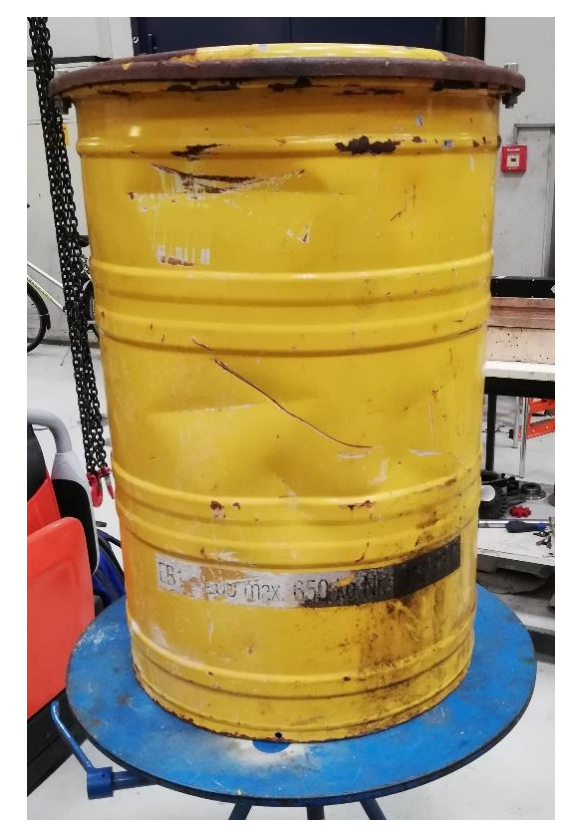

Aproach:

- Automatical detection of damage to new and stored drums

- categorization

- If necessary, initiate consequences to minimize damage 


\section{Goals of the research project}

- Increase in Safety during interim storage of nuclear waste

- All-round, objective (reproducible), optical inspection with parallel documentation and archiving

- Backtracking of damage development by continuous monitoring

- Prevent the drums from loss of integrity

- Increase in occupational safety: staff ist less exposed to radiation

- Automation

- Time Gain in the inspection of the drums

- Automatical handling; evaluation of entire drum surface

- electronical storage and documentation of the results

- Output of inspection report 


\section{Concept}

\section{- Requirements}

- Mobile inspection unit

- Optical and geometrical recording of the whole drum surface, including top (lid) and bottom, to detect damage like:

- Corrosion

- Bumps / wells

- Scratches / cracks

- Collected data will be automatically analyzed by a software, digitally saved and an inspection report will be generated

\section{Boundary conditions of the research project}

200 L-drums (A200, R200, RRF200)

- Low active waste 


\section{Concept}

\section{- Setting of inspection unit and components}
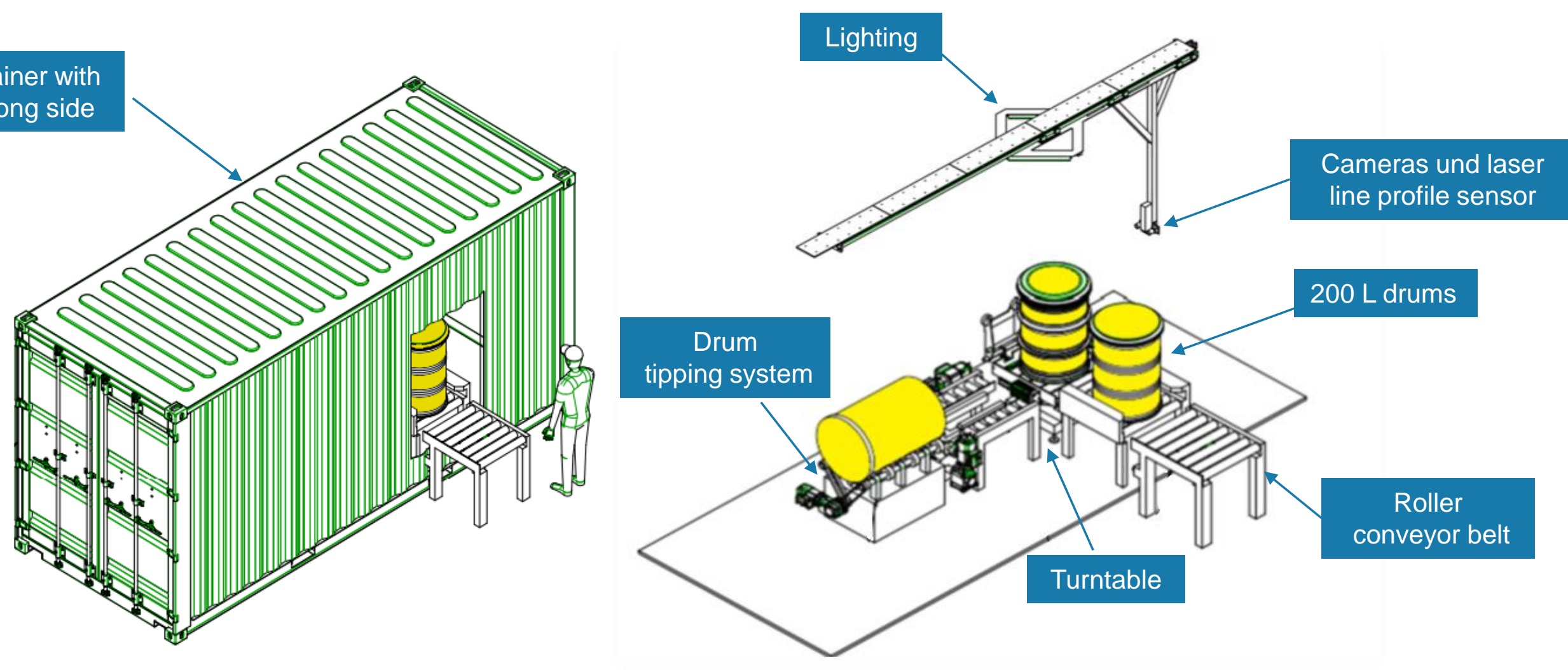


\section{Inspection process}

Step 1 - Drum is carried to the turntable and gets centered
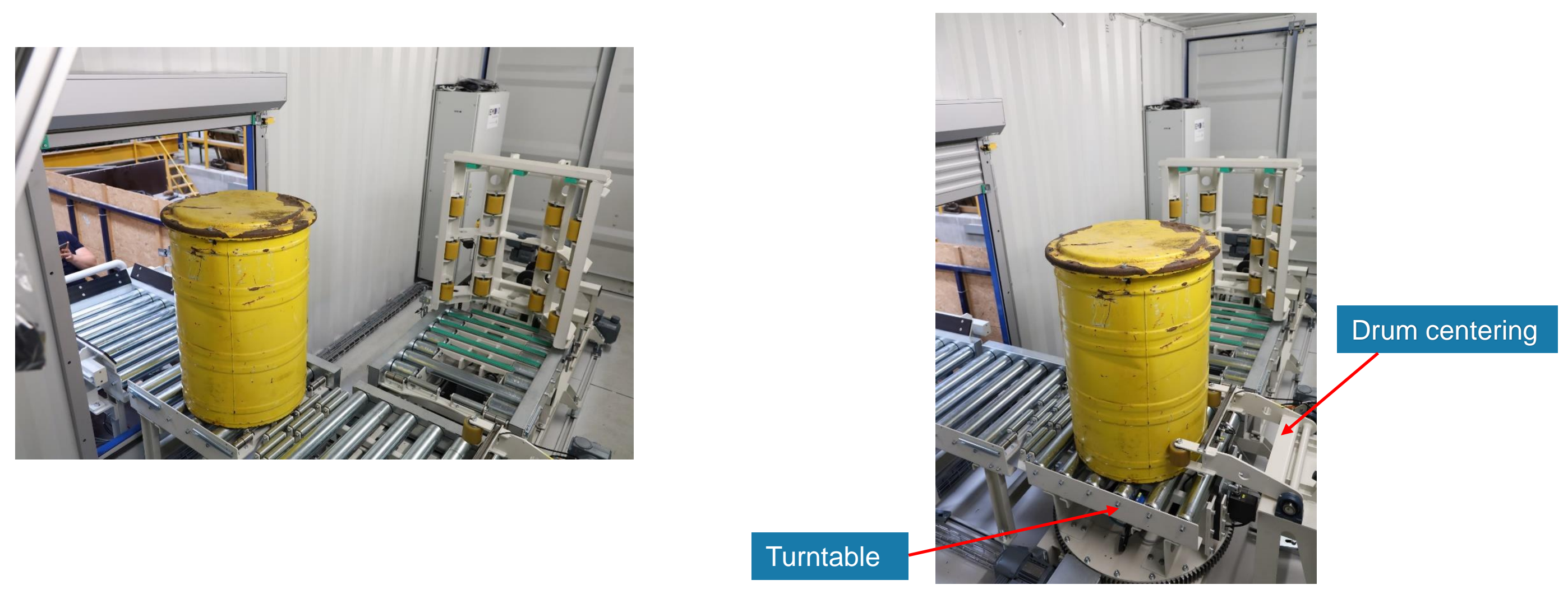


\section{Inspection process}
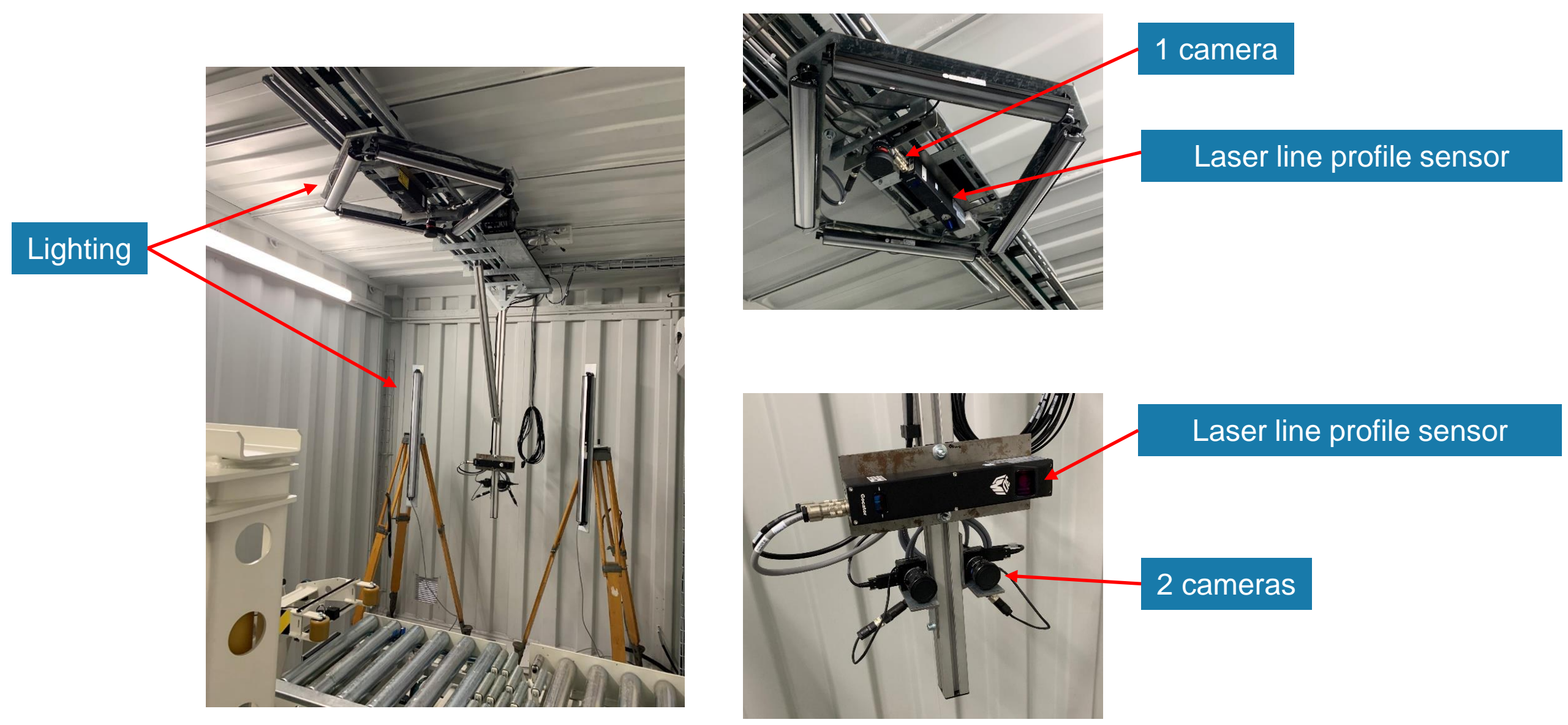


\section{Inspection process}

\section{Step 1.1 - Drum coat und drum top scan}

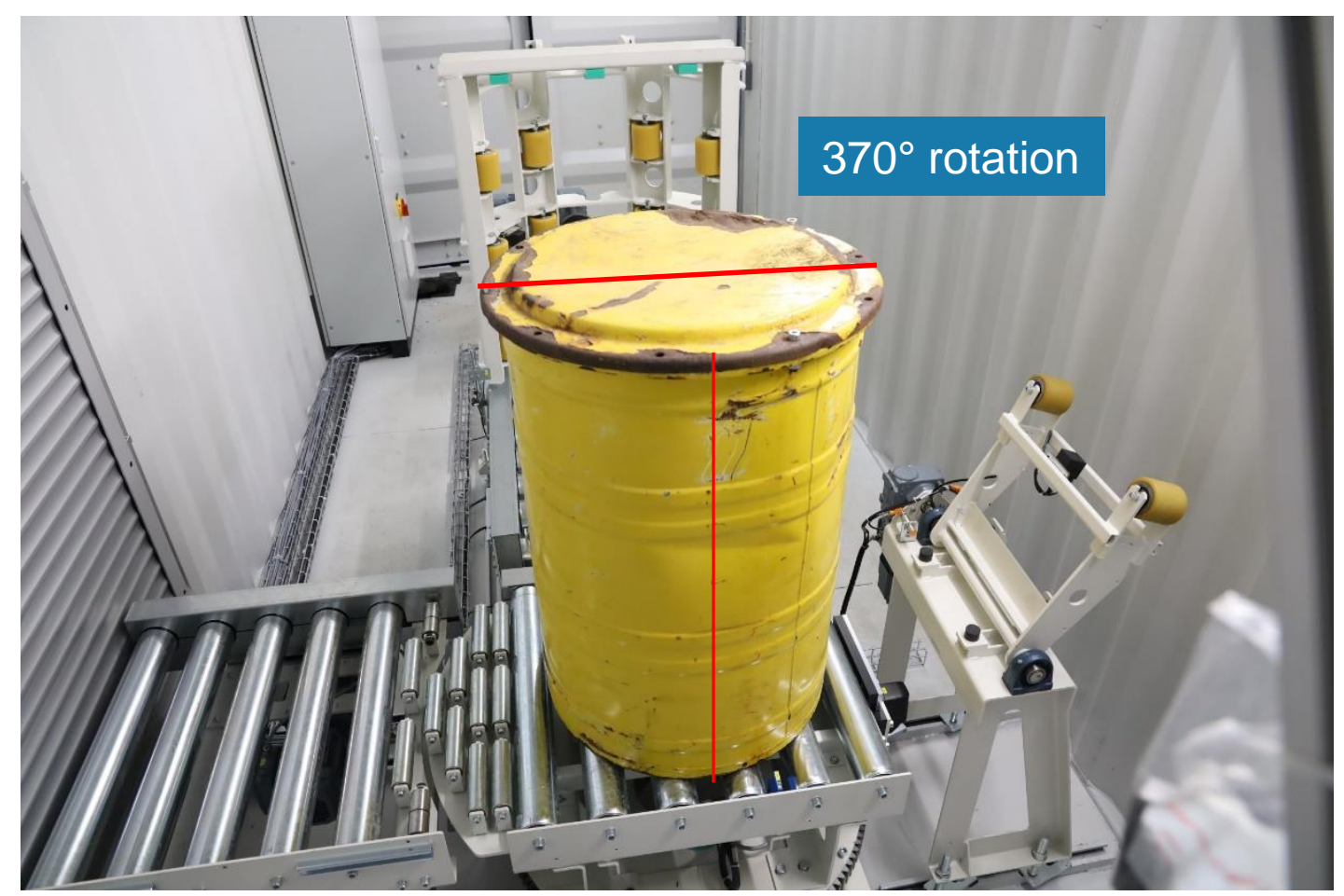




\section{Pre-tests result}

Elevation map of the unwound drum coat - New drum
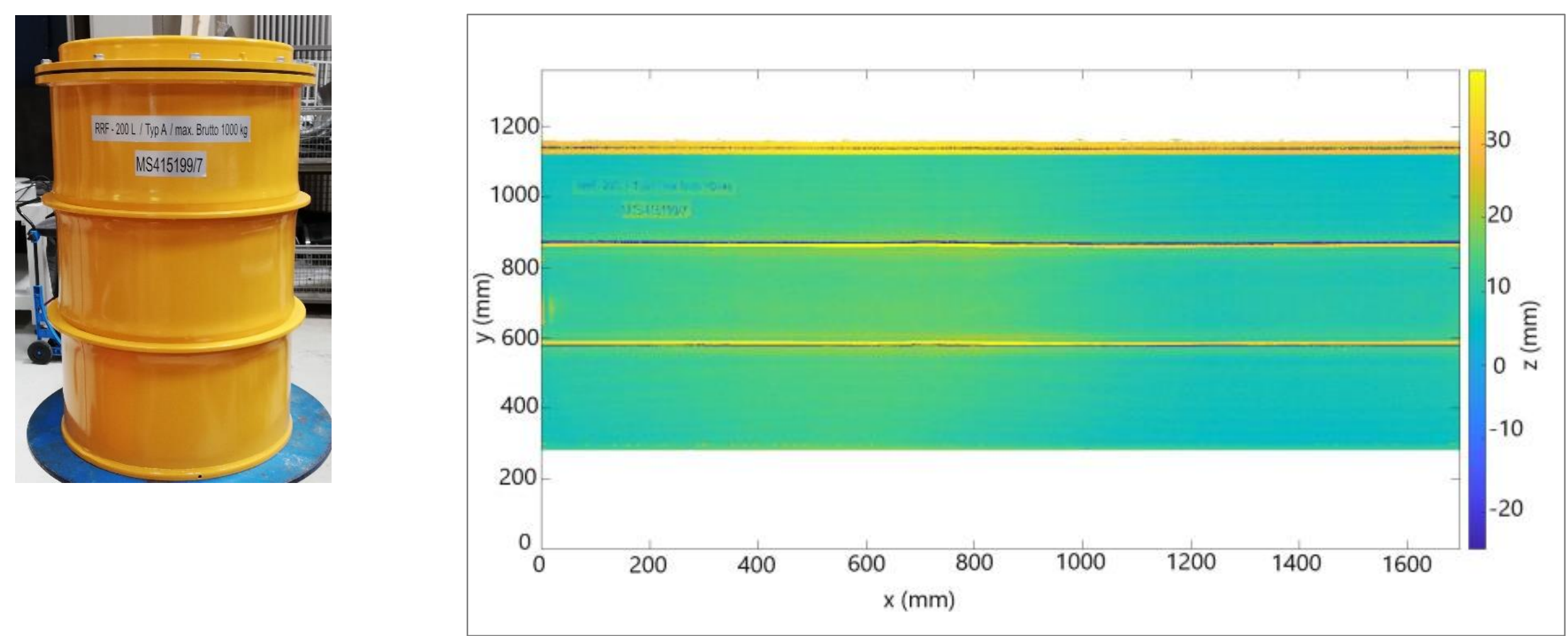


\section{Pre-tests result}

Elevation map of the unwound drum coat - Used drum
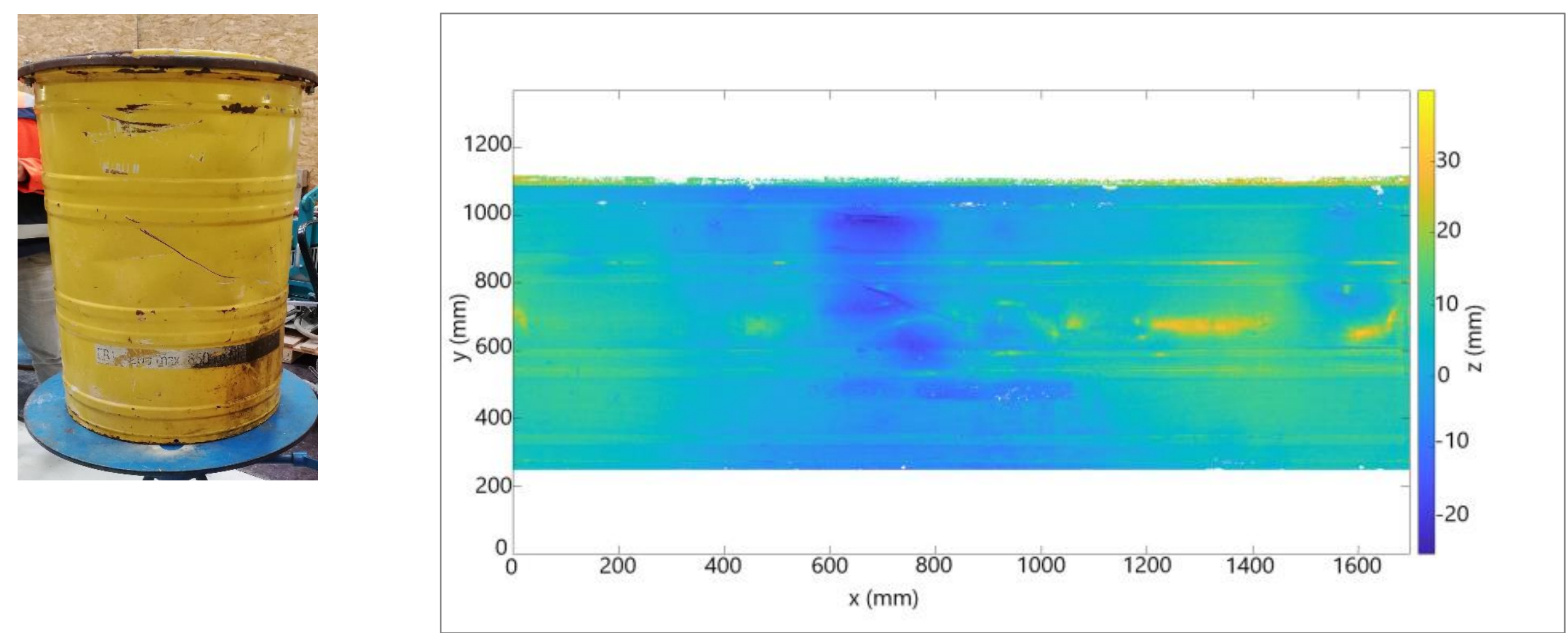


\section{Inspection process}

Step 1.2 - Drum coat und drum top photograph

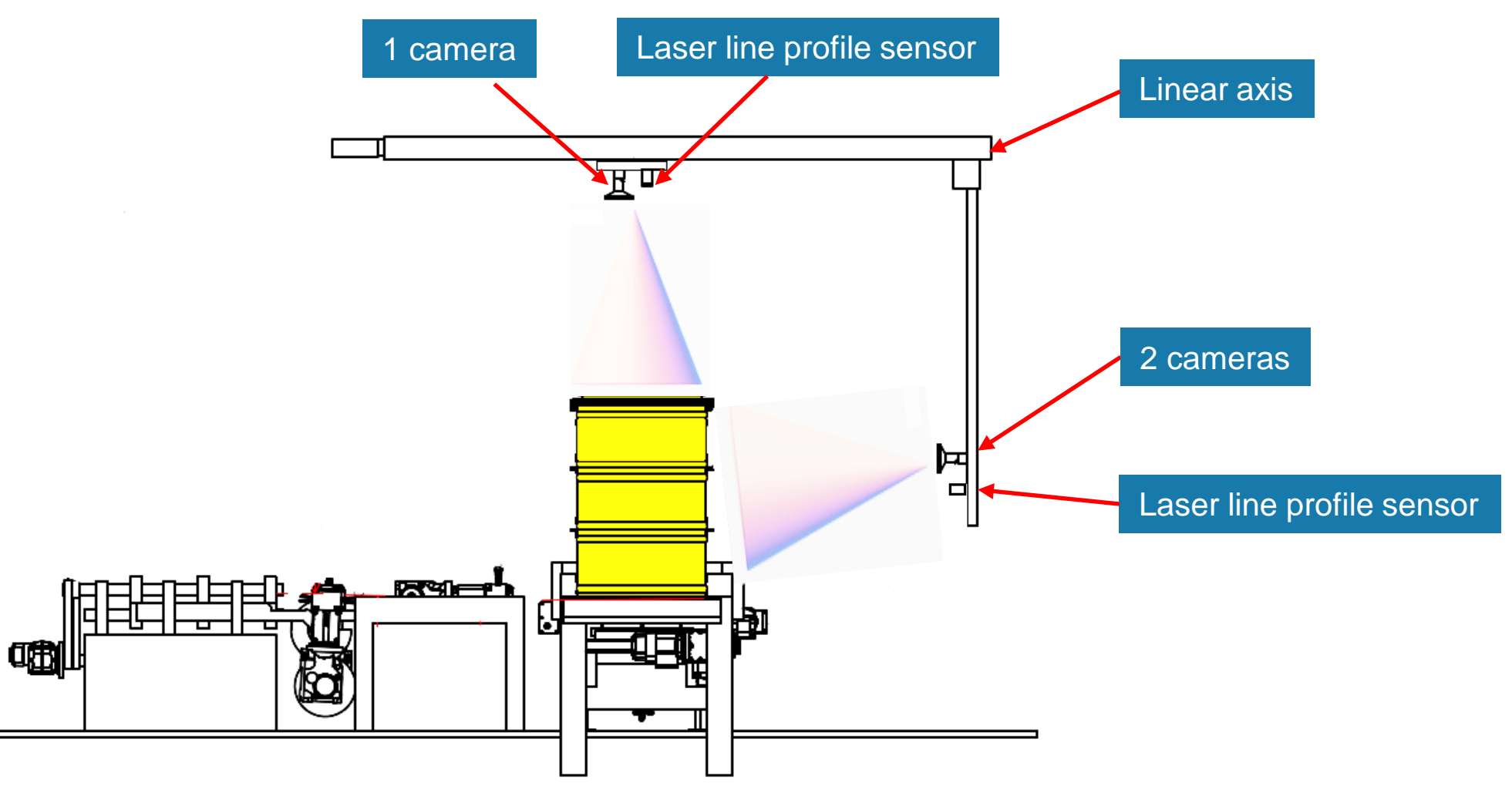




\section{Pre-tests result}

- Profile of the drum top with texture
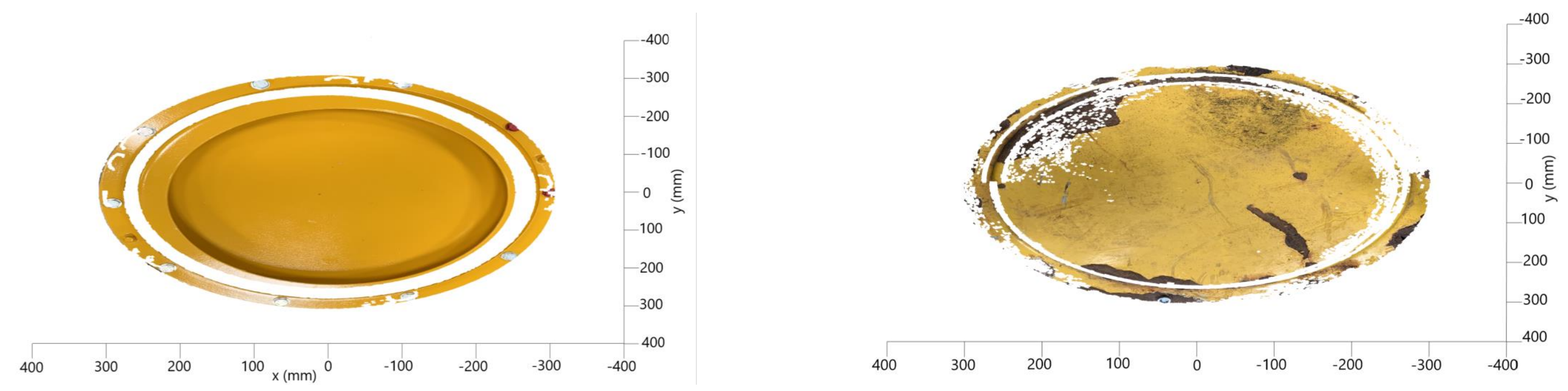


\section{Inspection process}

Step 2: Drum is carried to the tipping system and gets tipped
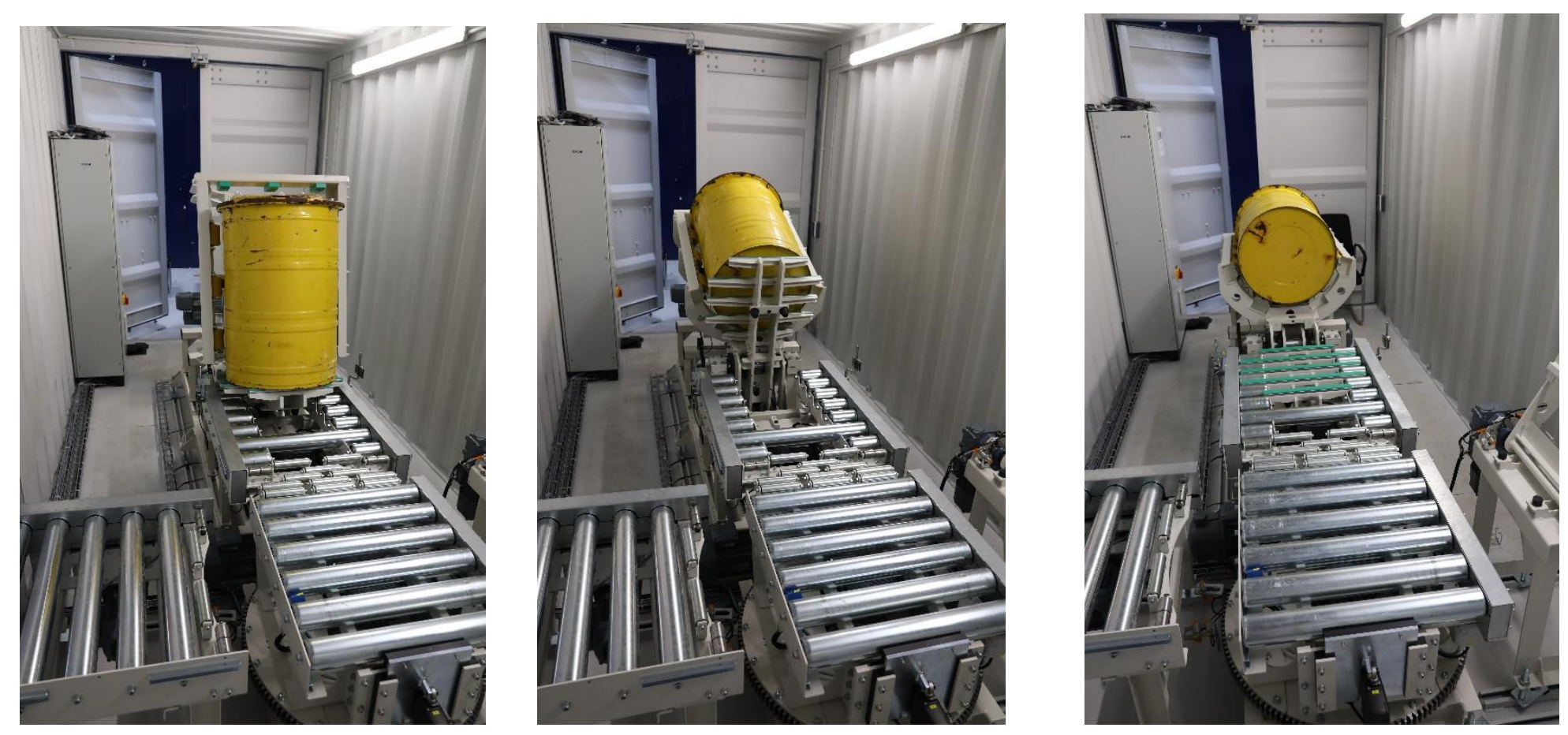


\section{Inspection process}

Step 2.1 - Drum botton scan und photograph

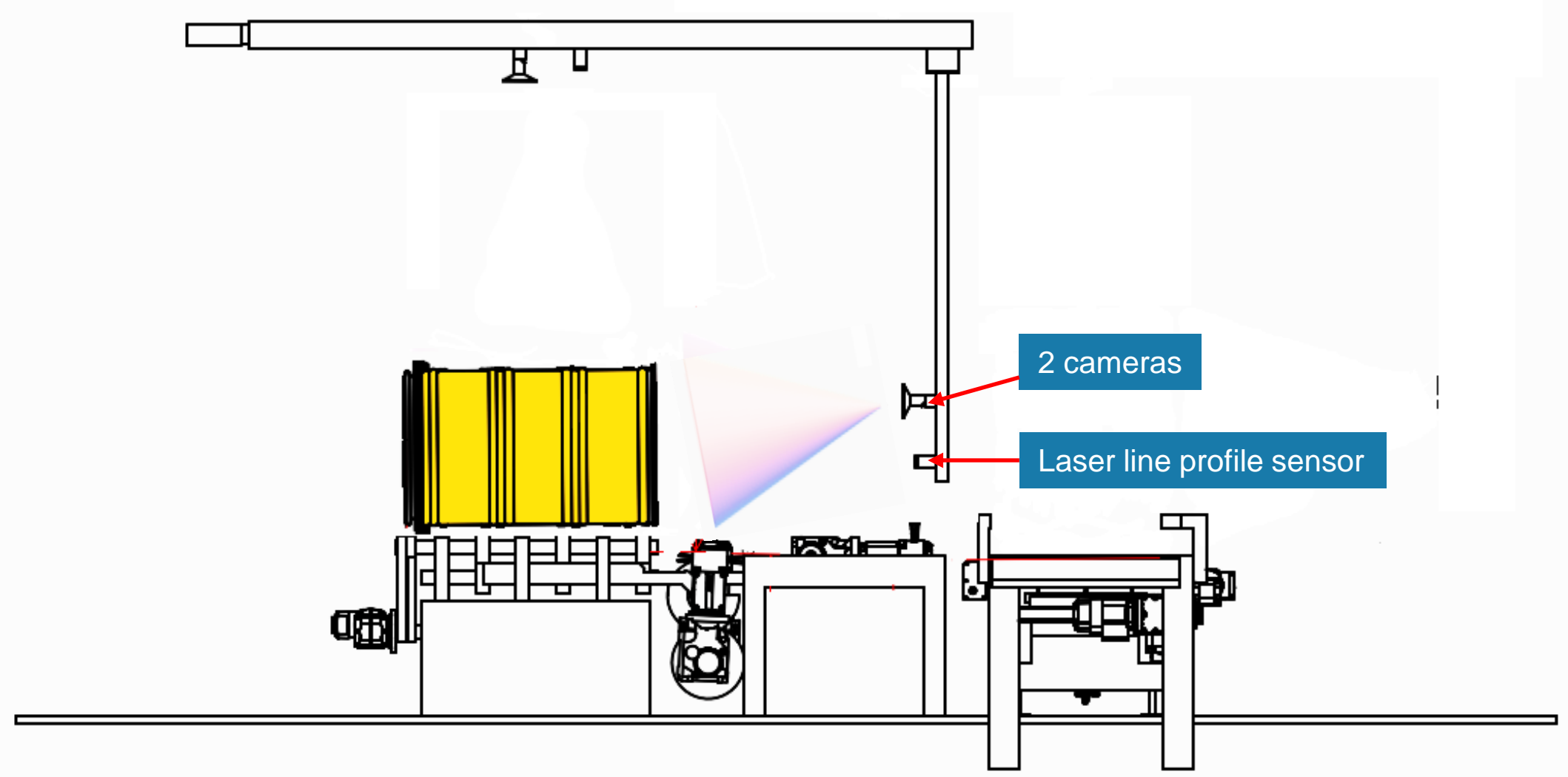




\section{Outlook}

\section{Time line}

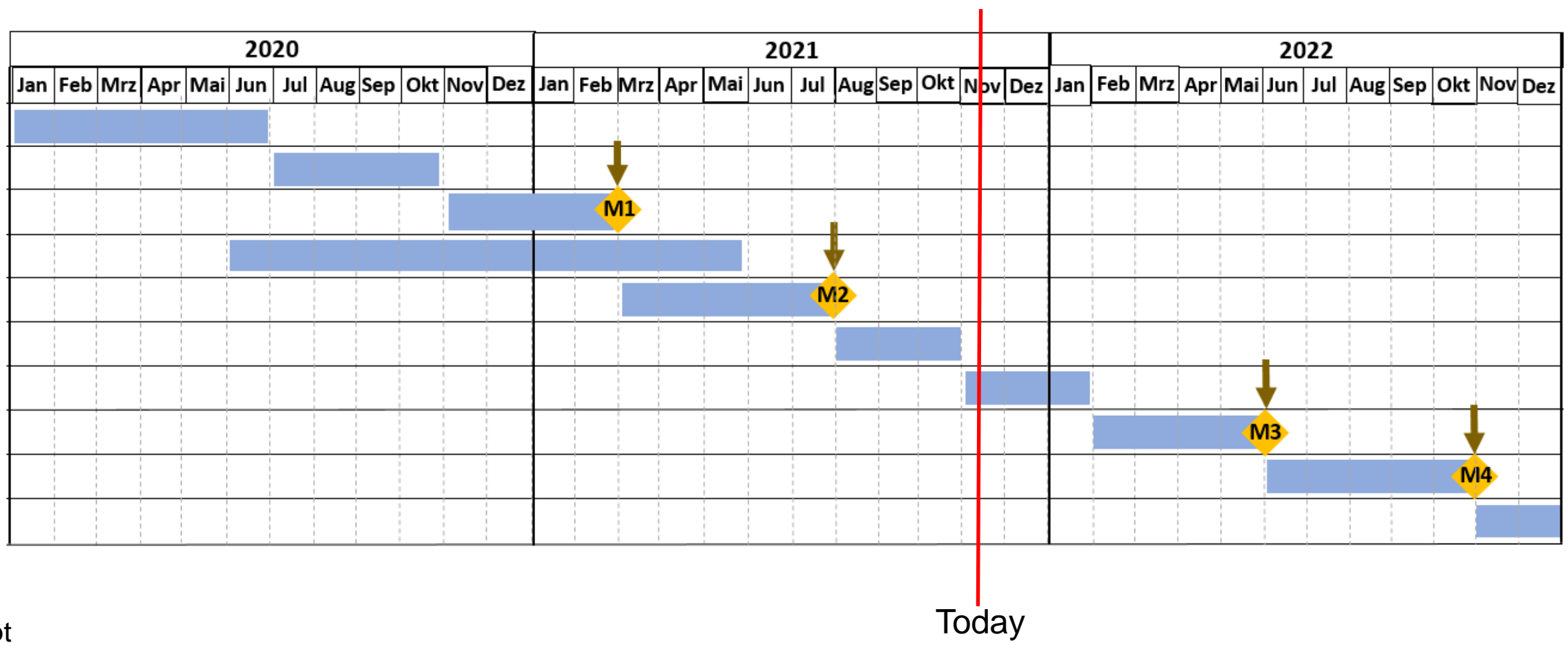

M1 Finished Concept

M2 Demonstrator 1.0

M3 Final maturity Demonstrator 1.0

M4 Final maturity Demonstrator 2.0 


\section{Thank you very much for your attention!}

